07;09

\title{
Изучение влияния допирования калием на характеристики перовскитного солнечного элемента
}

\author{
() М.Ф. Вильданова, А.Б. Никольская, С.С. Козлов, О.К. Карягина, О.И. Шевалеевский \\ Институт биохимической физики им. Н.М. Эмануэля РАН, Москва, Россия \\ E-mail: mvildanova@sky.chph.ras.ru
}

Поступило в Редакцию 27 ноября 2019г.

В окончательной редакции 27 ноября 2019г.

Принято к публикации 2 декабря 2019 г.

\begin{abstract}
Разработаны перовскитные солнечные элементы с фотоактивным слоем перовскита, допированным ионами калия. Установлено, что допирование влияет на структуру и морфологию перовскитного слоя, увеличивая размеры кристаллитов и однородность поверхности. Показано, что в допированных образцах наблюдается снижение рекомбинационных потерь, увеличивающее эффективность фотопреобразования и стабильность работы солнечного элемента.
\end{abstract}

Ключевые слова: перовскит, солнечный элемент, допирование.

DOI: 10.21883/PJTF.2020.05.49105.18134

Гибридные органо-неорганические материалы со структурой перовскита $A B X_{3}$ (где $X\left(\mathrm{Br}^{-}, \mathrm{I}^{-}, \mathrm{Cl}^{-}\right)-$ анион, $A\left(\mathrm{MA}^{+}, \mathrm{FA}^{+}, \mathrm{Cs}^{+}\right)$и $B\left(\mathrm{~Pb}^{2+}, \mathrm{Sn}^{2+}\right)$ - катионы различных размеров) широко используются для создания фотопреобразователей последнего поколения перовскитных солнечных элементов (ПСЭ). Эффективность ПСЭ, сравнимая с эффективностью традиционных солнечных элементов на основе кремния, обусловлена высокой электропроводностью и сильным оптическим поглощением перовскитного слоя в видимой области спектра. Параметры фотоактивного перовскитого слоя существенно зависят от технологии нанесения, его морфологии и структуры. В связи с этим большое количество исследований посвящено улучшению кристалличности, однородности и качества слоя, в том числе с помощью внедрения ионов металлов (допирования) [1,2]. В работах исследуются вопросы допирования каждого из $A$-, $B$ - и $X$-узлов системы, в частности проблемы частичного замещения иона $\mathrm{Pb}^{2+}[3,4]$, а также допирования структуры $\mathrm{CH}_{3} \mathrm{NH}_{3} \mathrm{PbI}_{3}$ щелочными металлами $[5,6]$. Внедрение щелочных металлов улучшает кристалличность перовскитного слоя благодаря рекристаллизации мелких зерен, что снижает рекомбинационные потери и повышает эффективности фотопреобразования ПСЭ [7].

В настоящей работе приготовлены образцы ПСЭ с использованием фотоактивных перовскитных слоев, допированных калием, и проведены исследования их фотовольтаических параметров в сравнении с ПСЭ на основе недопированных систем.

Подробное описание процесса изготовления ПСЭ представлено в наших предыдущих работах [8,9]. Допирование $\mathrm{CH}_{3} \mathrm{NH}_{3} \mathrm{PbI}_{3}$ ионами калия проводилось путем добавления $0.02 \mathrm{~mol}$ KI в $1.2 \mathrm{M}$ раствор прекурсора перовскита. С использованием допированных фотоактивных слоев перовскита были сконструированы ПСЭ со структурой стекло/FTO/TiO $2 / \mathrm{CH}_{3} \mathrm{NH}_{3}(\mathrm{~Pb}: \mathrm{K}) \mathrm{I}_{3} /$ spiro-
$\mathrm{MeOTAD} / \mathrm{Au}$ (где FTO - допированный фтором оксид олова (fluorine doped tin oxide), spiro-MeOTAD $\mathrm{C}_{81} \mathrm{H}_{68} \mathrm{~N}_{4} \mathrm{O}_{8}$, материал с дырочной проводимостью), а также контрольные образцы ПСЭ на основе недопированных систем. Все образцы были изготовлены в условиях воздушной атмосферы при повышенной влажности $(\sim 40 \%)$. Морфология поверхности перовскитных слоев была изучена с помощью сканирующего электронного микроскопа (CЭM) Hitachi SU8000 (Япония). Структурные характеристики полученных материалов исследовались методом рентгенофазового анализа на порошковом дифрактометре ДРОН-3 (Буревестник, Россия) при комнатной температуре в монохроматическом $\mathrm{Cu} K_{\alpha}$-излучении $(35 \mathrm{kV}, 28 \mathrm{~mA})$. Измерения фотовольтаических параметров ПСЭ проводились в стандартных условиях освещения AM1.5G $\left(1000 \mathrm{~W} / \mathrm{m}^{2}\right)$ с использованием имитатора солнечного излучения Abet Technologies Solar Simulator (США). Вольт-амперные характеристики (BAX) записывались на измерительной системе Keithley 4200-SCS (США). Спектры внешней квантовой эффективности IPCE (incident photon-to-current conversion efficiency) были записаны на автоматизированной системе QEX10 (PV Measurements, США) в диапазоне длин волн 300-850 nm. Исследования стабильности работы ПСЭ проводились на воздухе в отсутствие воздействий УФ и повышенной температуры на образцы в течение 45 дней путем периодических измерений ВАХ.

Исследования поверхности перовскитных слоев показали, что допирование существенно влияет на морфологию слоя, увеличивает размеры кристаллитов, уменьшает протяженность границ зерен и таким образцом снижает концентрацию поверхностных состояний. Микрофотография поверхности пленки $\mathrm{CH}_{3} \mathrm{NH}_{3}(\mathrm{~Pb}: \mathrm{K}) \mathrm{I}_{3}$ приведена на рис. $1, a$. Средний размер зерен составляет около $350 \mathrm{~nm}$, что значительно превосходит соответствующее значение для недопированного $\mathrm{CH}_{3} \mathrm{NH}_{3} \mathrm{PbI}_{3}$ 
Фотовольтаические параметры ПСЭ на основе допированного калием и недопированного перовскитного слоя

\begin{tabular}{c|c|c|c|c}
\hline $\begin{array}{c}\text { Состав } \\
\text { перовскитного слоя }\end{array}$ & $J_{s c}, \mathrm{~mA} / \mathrm{cm}^{2}$ & $V_{\text {oc }}, \mathrm{V}$ & $\eta$, a.u. \\
\hline $\mathrm{CH}_{3} \mathrm{NH}_{3} \mathrm{PbI}_{3}$ & 17.44 & 0.923 & 0.649 & 10.45 \\
$\mathrm{CH}_{3} \mathrm{NH}_{3}(\mathrm{~Pb}: \mathrm{K}) \mathrm{I}_{3}$ & 19.07 & 0.921 & 0.687 & 12.07
\end{tabular}

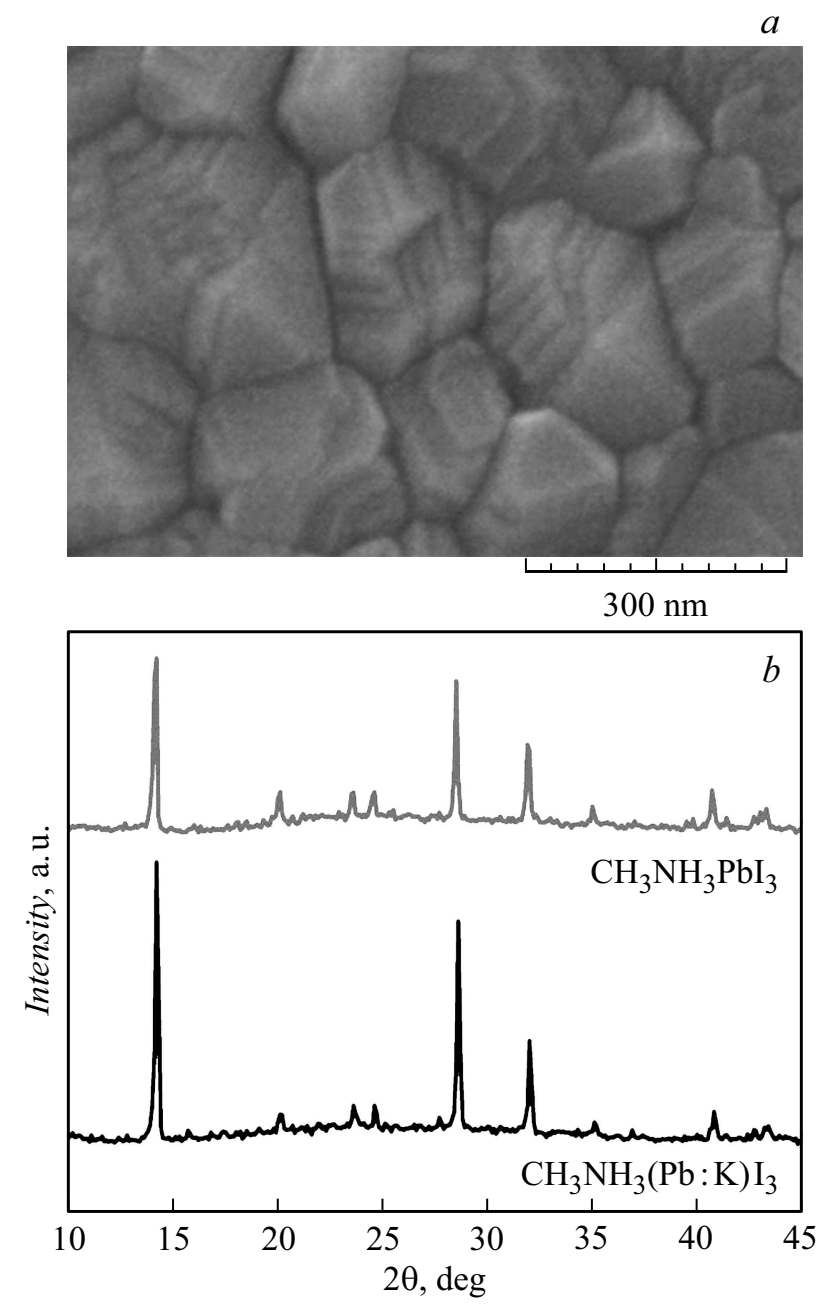

Рис. 1. СЭМ-изображение поверхности допированного калием перовскитного слоя $($ a) и сравнительные спектры рентгенофазового анализа для допированного калием и недопированного перовскитного слоя $(b)$.

( $220 \mathrm{~nm})$. Таким образом, внедрение в систему ионов калия оказывает положительный эффект на рост кристаллов и однородность перовскитного слоя.

На рис. 1,b приведены дифрактограммы образцов допированного и недопированного перовскита. Для недопированных перовскитных слоев наблюдаются сильные дифракционные пики при 14.15, 28.50 и 31.94º, которые отвечают плоскостям кристалла тетрагонального перовскита (110), (220) и (310) соответственно и указывают на высокую кристалличность структуры.
Характеристический пик $\mathrm{PbI}_{2}$ при $12.6^{\circ}$ отсутствует, что свидетельствует о высоком качестве полученной пленки. Допирование $\mathrm{CH}_{3} \mathrm{NH}_{3} \mathrm{PbI}_{3}$ ионами калия приводит к изменению дифракционной картины. Указанные характерные пики становятся более узкими, значительно увеличивается их интенсивность. Это свидетельствует об увеличении размера кристаллитов. При этом в спектрах не было обнаружено никаких дополнительных примесных фаз. Таким образом, результаты рентгенофазового анализа образцов демонстрируют позитивное влияние допирования на структурные параметры перовскитного материала.

Серия допированных ионами калия ПСЭ со структурой типа стекло/FTO/ $/ \mathrm{TiO}_{2} / \mathrm{CH}_{3} \mathrm{NH}_{3}(\mathrm{~Pb}: \mathrm{K}) \mathrm{I}_{3} /$ spiro$\mathrm{MeOTAD} / \mathrm{Au}$ и контрольная серия ПСЭ были сконструированы на открытом воздухе в условиях повышенной влажности $(\sim 40 \%)$. Вольт-амперные характеристики ПСЭ для стандартного освещения AM1.5G представлены на рис. 2. Максимальные значения эффективности, полученные для допированных образцов и контрольной серии, составили 12.07 и $10.45 \%$ соответственно. Рекордные фотоэлектрические параметры для ПСЭ обоих типов приведены в таблице. Видно, что в допированных образцах наблюдаются повышенные значения коэффициента заполнения $(F F)$ и плотности тока короткого замыкания $\left(J_{s c}\right)$, что объясняется улучшением морфологии перовскитного слоя и его более высокой кристалличностью вследствие допирования ионами калия [10], а также увеличением шунтирующего сопротивления и снижением рекомбинационных потерь. При этом напряжение холостого хода $\left(V_{o c}\right)$ остается практически неизменным. Также в допированных образцах ПСЭ наблюдается улучшенная спектральная характеристика внешней квантовой эффективности. В результате для ПСЭ, приготовленных с использованием допированных фотоактивных слоев, эффективности фотопреобразования увеличились примерно на $15 \%$.

При измерении ВАХ допированных калием ПСЭ было изучено явление гистерезиса, стандартно наблюдающегося для классических недопированных образцов ПСЭ вследствие захвата носителей заряда, миграции ионов и т.д. Как видно из рис. 2, $a$, для допированных образцов не наблюдается значительных различий при прямом и обратном ходе сканирования. Уменьшение эффекта гистерезиса по сравнению с недопированными образцами ПСЭ (рис. 2,b) мы также связываем с улучшенным качеством допированного перовскитного слоя, в котором вследствие увеличения размеров кристал- 

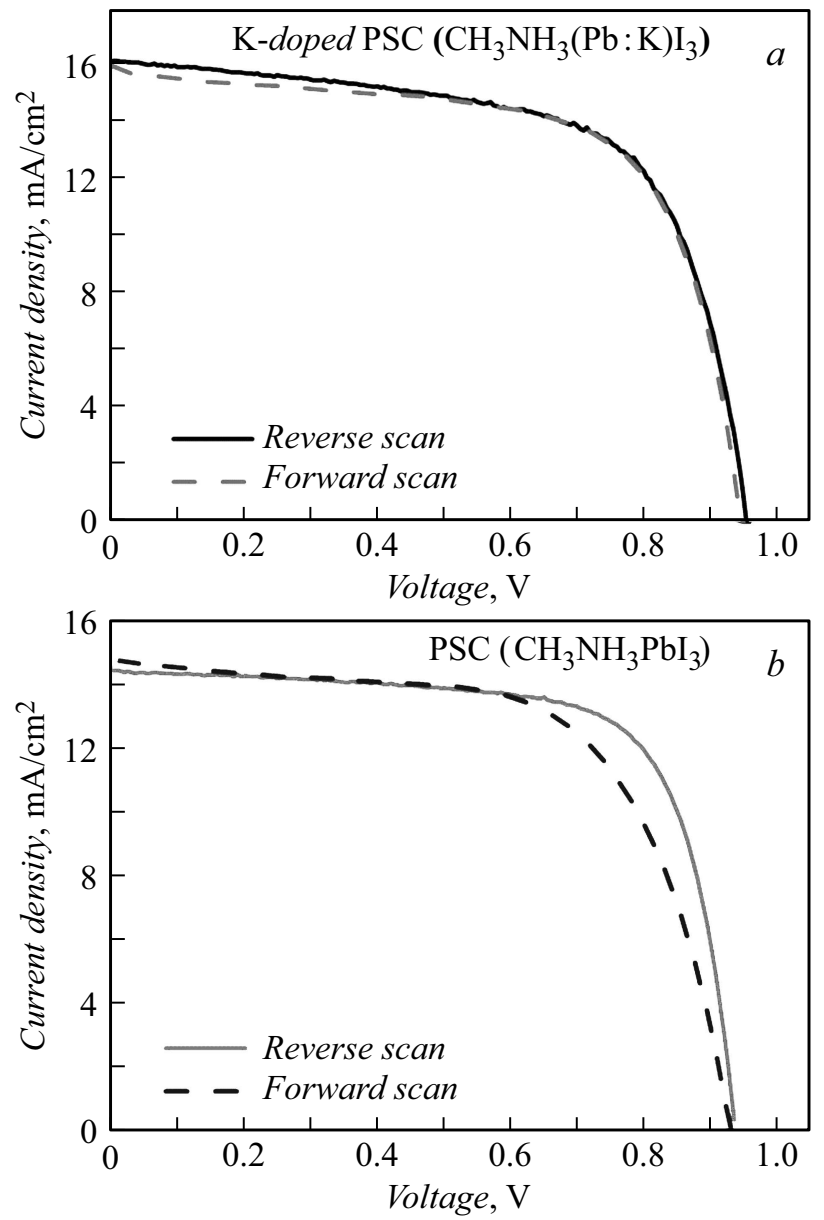

Рис. 2. Сравнительные ВАХ ПСЭ на основе допированных калием $(a)$ и недопированных $(b)$ перовскитных слоев, записанные в условиях прямого (штриховая линия) и обратного (сплошная линия) хода сканирования.

литов снижается плотность поверхностных дефектов на границах зерен. Это в свою очередь уменьшает концентрацию электронных ловушек, ответственных за эффекты гистерезиса [11].

Сравнительные исследования стабильности ПСЭ показали, что в условиях повышенной влажности эффективность фотопреобразования допированных ПСЭ падает в среднем на $10 \%$ (для недопированных образцов на $30 \%$ ). Соответствующие графики деградации на воздухе фотовольтаических параметров ПСЭ представлены на рис. 3,a. В ПСЭ деградация образцов выражается в первую очередь в снижении $J_{s c}$. В структурном плане последнее является результатом воздействий атмосферной влажности, приводящей к частичному разложению перовскита на $\mathrm{PbI}_{2}$ и летучие фракции $\mathrm{CH}_{3} \mathrm{I}$ и $\mathrm{NH}_{3}$, что приводит к существенному снижению электропроводности перовскитного слоя. Снижение $F F$ также обусловлено образованием в процессе деградации структурных дефектов в слое перовскита, что инициирует прямой контакт между электронопроводящим и дырочнопроводящим слоями и понижает шунтирующее сопротив- ление. Графики деградации на воздухе допированных калием ПСЭ демонстрируют более высокую стабильность $J_{s c}$ и $F F$ (рис. 3,b). Полученные результаты подтверждают, что допирование щелочными металлами приводит к повышению стойкости к окислению перовскитного слоя [12]. Таким образом, примененное нами допирование перовскитного материала в ПСЭ ионами калия позволило не только значительно улучшить фотовольтаические параметры элемента, но и увеличить стабильность его работы за счет подавления деградационных процессов.

В результате нами были приготовлены допированные ионами калия фотоактивные слои перовскита $\mathrm{CH}_{3} \mathrm{NH}_{3} \mathrm{PbI}_{3}$ и сконструированы ПСЭ на их основе. Сравнительные исследования фотовольтаических характеристик ПСЭ на основе допированных и недопированных фотоактивных слоев показали существенные преимущества применения допированных систем. Установлено, что допирование приводит к улучшению структурных и морфологических характеристик перовскитного слоя, что выражается в снижении рекомбинационных потерь и улучшении транспортных характеристик фотоактивного слоя. Кроме того, ПСЭ на основе допированных
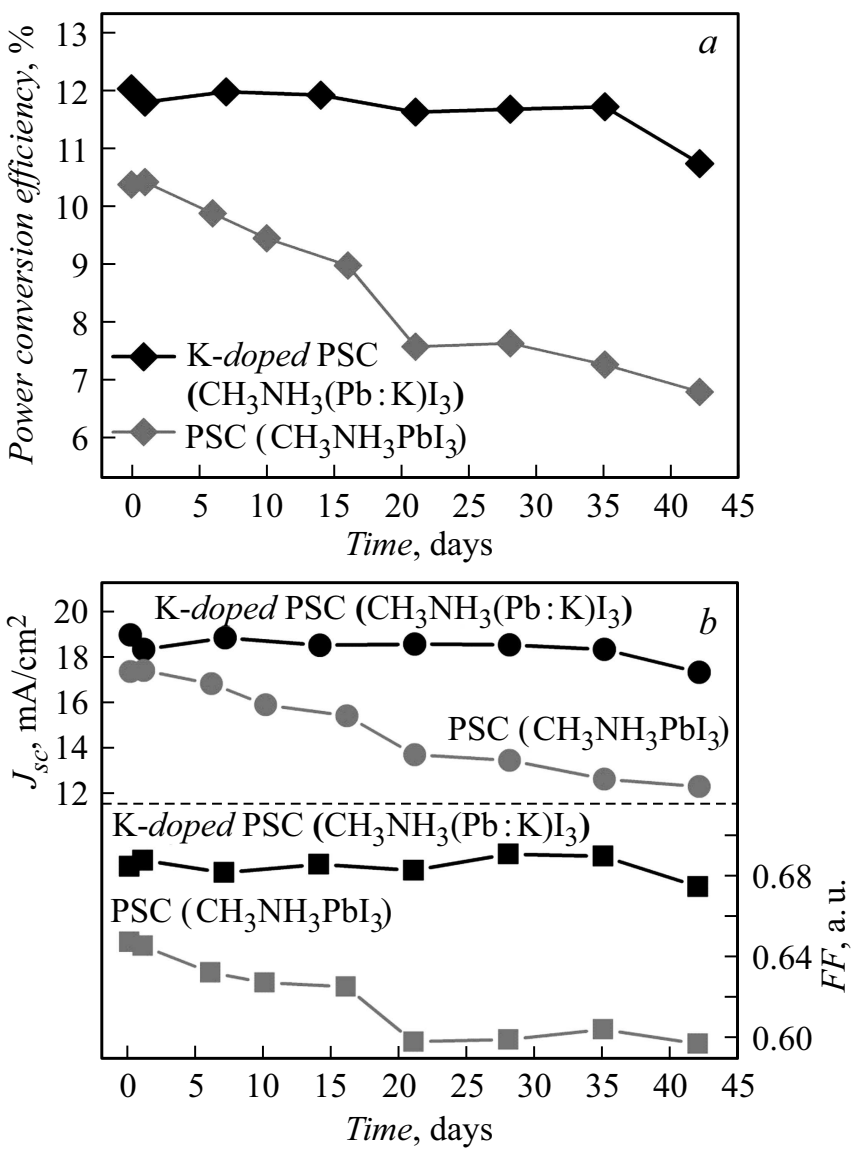

Рис. 3. Сравнительные графики деградации на воздухе фотовольтаических параметров ПСЭ на основе допированных калием и недопированных перовскитных слоев: эффективность фотопреобразования $(a)$, плотность фототока и фактор заполнения $\mathrm{BAX}(b)$. 
слоев продемонстрировали значительно более высокую стабильность при работе в условиях влажной атмосферы по сравнению с недопированными образцами. Таким образом, использование в ПСЭ допированных ионами калия фотоактивных слоев перовскита позволило увеличить стабильность элементов и повысить эффективность фотопреобразования на $15 \%$.

\section{Финансирование работы}

Исследование выполнено при финансовой поддержке Российского научного фонда (проект № 17-19-01776).

\section{Конфликт интересов}

Авторы заявляют, что у них нет конфликта интересов.

\section{Список литературы}

[1] Wang J.T.W., Wang Z., Pathak S., Zhang W., de Quilettes D.W., Wisnivesky-Rocca-Rivarola F., Huang J., Nayak P.K., Patel J.B., Mohd Yusof H.A., Vaynzof Y., Zhu R., Ramirez I., Zhang J., Ducati C., Grovenor C., Johnston M.B., Ginger D.S., Nicholas R.J., Snaith H.J. // Energy Environment. Sci. 2016. V. 9. N 9. P. 2892-2901.

DOI: $10.1039 / C 6 E E 01969 B$

[2] Aldibaja F.K., Badia L., Mas-Marzá E., Sánchez R.S., Barea E.M., Mora-Sero I. // J. Mater. Chem. A. 2015. V. 3. N 17. P. 9194-9200. DOI: 10.1039/C4TA06198E

[3] Frolova L.A., Anokhin D.V., Gerasimov K.L., Dremova N.N., Troshin P.A. // J. Phys. Chem. Lett. 2016. V. 7. N 21. P. 43534357. DOI: $10.1021 /$ acs.jpclett.6b02122

[4] Abdi-Jalebi M., Dar M.I., Sadhanala A., Senanayak S.P., Grätzel M., Friend R.H. // J. Vis. Exp. 2017. N 121. P. e55307. DOI: $10.3791 / 55307$

[5] Chang J., Lin Z., Zhu H., Isikgor F.H., Xu Q.H., Zhang C., Hao Y., Ouyang J. // J. Mater. Chem. A. 2016. V. 4. N 42. P. 16546-16552. DOI: 10.1039/C6TA06851K

[6] Zhao W., Yao Z., Yu F., Yang D., Liu S. // Adv. Sci. 2018. V. 5. N 2. P. 1700131 . DOI: $10.1002 /$ advs.201700131

[7] Boopathi K.M., Mohan R., Huang T.Y., Budiawan W., Lin M.Y., Lee C.H., Ho K.C., Chu C.W. // J. Mater. Chem. A. 2016. V. 4. N 5. P. 1591-1597. DOI: 10.1039/C5TA10288J

[8] Шевалеевский О.И., Никольская А.Б., Вильданова М.Ф., Козлов С.С., Алексеева О.В., Вишнёв А.А., Ларина Л.Л. // Хим. физика. 2018. Т. 37. № 8. С. 36-42. DOI: $10.1134 / \mathrm{S} 0207401 \mathrm{X} 18080186$

[9] Никольская А.Б., Козлов С.С., Вильданова М.Ф., Шевалеевский О.И. // ФТП. 2019. Т. 53. В. 4. С. 550-554. DOI: 10.21883/FTP.2019.04.47456.9023

[10] Nazem H., Dizaj H.P., Gorji N.E. // Superlatt. Microstruct. 2019. V. 128. P. 421-427. DOI: 10.1016/j.spmi.2019.02.002

[11] Kim H.S., Park N.G. // J. Phys. Chem. Lett. 2014. V. 5. N 17. P. 2927-2934. DOI: $10.1021 / \mathrm{jz} 501392 \mathrm{~m}$

[12] Saliba M., Matsui T., Domanski K., Seo J.Y., Ummadisingu A., Zakeeruddin S.M., Correa-Baena J.P., Tress W.R., Abate A., Hagfeldt A., Grätzel M. // Science. 2016. V. 354. N 6309. P. 206-209. DOI: 10.1126/science.aah5557 